\title{
The Lord's Resistance Army and Forced Conscription in Northern Uganda
}

\author{
Phuong N. Pham, * Patrick Vinck** \& Eric Stover***
}

\begin{abstract}
On 13 October 2005, the International Criminal Court unsealed warrants of arrest for five senior leaders of the Lord's Resistance Army (LRA) for the forced conscription of children and other war crimes in northern Uganda. We compiled a database of 25,231 children and youth who had been registered by receptions centers in northern Uganda after their return from the LRA. Most of the LRA returnees were thirteen to eighteen years old (37 percent) and nineteen to thirty years old (24 percent). Twenty-four percent of the LRA returnees were female and 76 percent were male. The average length of abduction was 342 days, and the median number of days of abduction was ninety-two days. Among women aged nineteen to thirty years old, the average length of abduction was four and one half years. At the multivariate level, gender, age, and the interaction between them were associated with length of captivity (F-Statistic $=229.8, p$-value $=0.0001)$. Using triangulation methods, we estimate the LRA abducted 54,000 to 75,000 people, including 25,000 to 38,000 children, into their ranks between 1986 and 2006 .
\end{abstract}

* Phuong N. Pham, M.P.H. Ph.D. is a Research Associate Professor at the Payson Center for International Development, Tulane University and a Senior Research Fellow at the Human Right Center of the University of California, Berkeley.

** Patrick Vinck, Ph.D. is Director of the Berkeley-Tulane Initiative on Vulnerable Populations at University of California, Berkeley and Adjunct Professor at the Payson Center for International Development, Tulane University.

***Eric Stover is Faculty Director of the Human Rights Center and Adjunct Professor of Law and Public Health at the University of California, Berkeley.

We wish to thank the reception centers for sharing their data with us. This project would not have been possible without Lisa Peterson and Mychelle Balthazard who worked with the reception centers to improve their database capacity. We extend our gratitude to Michael Copeland, Andrew Mawson, and Cornelius William at UNICEF for their advice and assistance in northern Uganda. This study was conducted with funding from the John D. and Catherine T. MacArthur Foundation and The Sandler Family Supporting Foundation. The sponsors of the study had no role in the design of the study, data collection, data analysis, data interpretation, or writing of the report. 


\section{BACKGROUND}

Forced conscription of children and youth ${ }^{1}$ in the course of displacement is a common feature of armed conflicts. ${ }^{2}$ Since the late 1980s, the Lord's Resistance Army (LRA), a spiritualist rebel group, has abducted tens of thousands of children and adults in northern Uganda to serve as porters and soldiers. Rebel commanders have forced girls, some as young as twelve years old, to serve as sexual and domestic servants and forced their fighters to kill and inflict horrific injuries by cutting off the ears, noses, lips, and limbs of defenseless civilians. The experience of forced conscription into the LRA is traumatic and varies in scope and intensity, resulting in a high prevalence of post-traumatic stress disorder (PTSD) symptoms. ${ }^{3}$ On 13 October 2005, the International Criminal Court unsealed the warrants of arrest for five senior LRA leaders for crimes against humanity, including the forced conscription of children. ${ }^{4}$

Since the mid-1990s, twelve reception centers have been established to receive LRA returnees. A special Child Protection Unit of the Ugandan People's Army (UPDF) delivers to the reception centers children and youth that have been captured in gun battles or escaped from the LRA. Upon arrival, the returnees are given a medical exam and treated for diseases and other ailments. Those suffering from war wounds are sent to hospitals in Gulu and Kampala. Most returnees stay at the centers for two to six weeks. During that time, staff members attempt to trace the whereabouts of their parents or relatives. Boys and girls are housed in separate units, and usually spent the day together undertaking a range of activities, including counseling, song and dance, sports, and vocational training.

\section{METHODS}

The authors of this article collected and analyzed data on LRA returnees from eight of the nine reception centers that were still in operation at the time of research in 2006 . (One reception center opted not to participate in the study but provided aggregated statistics on the returnees they served. This center accounts for less than 10 percent of all registered LRA returnees

1. In northern Uganda, children are defined as those between the ages of five and twelve, and youth are defined as those between the ages of thirteen and thirty.

2. Graça Machel, Impact of War on Children (2001).

3. Ilse Derluyn, Eric Broekaert, Gilberte Schuyten \& Els De Temmerman, Post-Traumatic Stress in Former Ugandan Child Soldiers, 363 The Lancet 861 (2004); Patrick Vinck, Phuong Pham, Harvey Weinstein et al., Exposure to War Crimes and its Implications for Peace Building in Northern Uganda, 298 J. Am. MED. Ass'N. 543 (2007).

4. Press Release, ICC-20051014-110-En, Warrant of Arrest unsealed against five LRA Commanders, International Criminal Court, The Hague (14 Oct. 2005). 
in northern Uganda.) For the eight participating reception centers, paperbased data, where applicable, and existing digital information were imported into an integrated database. A total of 518 duplicated entries were deleted, resulting in a database of 22,759 registered LRA returnees. The total climbs to 25,231 if registered returnees from the nonparticipating reception center are included.

Descriptive statistics were used to present the characteristics of registered LRA returnees from the eight centers. Two-way analysis of variance (ANOVA) and curvilinear regression were used to better understand risk factors associated with abduction and to test the relationship between length of captivity and socio-demographic characteristics. The Committee of Human Subjects at the University of California, Berkeley and Tulane University approved the study.

This study has some limitations. The reception centers only started functioning in the mid-1990s and thus information about abducted and returned children and adults before this period is not included in the reception center databases. Reception centers also report that some paper-based intake forms were lost due to poor conservation. In addition, it is estimated that between $13^{5}$ and 43 percent $^{6}$ of all abducted children and youth pass through a reception center. Hence, the aggregated database does not reflect the total number of former abductees and does not constitute a random sample. Forms to collect information on former abducted people were not standard across reception centers. As a result, we were only able to examine seventeen variables common to all former abductees. During data cleaning, 518 cases were deleted as duplicate entries (same information on all seventeen fields). Another 337 cases were flagged but not deleted as possible duplicates.

\section{FINDINGS}

Most registered LRA returnees were thirteen to eighteen years old ( 37 percent) and nineteen to thirty years old ( 24 percent). Twenty-four percent of the former abductees were female and 76 percent were male. The mean age of females was sixteen years old (S.D. 7.0), with a median age of fifteen. The mean age of males was twenty years old (S.D. 8.6), with a median age of seventeen. The difference in mean age was statistically significant $(p<0.01)$.

5. Phuong Pham, Patrick Vinck, Eric Stover et al, When the War Ends: A Population-Based Survey on Peace, Justice, and Social. Reconstruction in Northern Uganda, Report by the Berkeley-Tulane Initiatives on Vulnerable Population and International Center for Transitional Justice (2007) [hereinafter WHEN THE WAR ENDS].

6. Jeannie Annan, Christopher Blattman \& Rocer Horton, The State of Youth and Youth Protection in Northern Uganda: Findings from the Survey for War Affected Youth, A Report for UNICEF (2006). 
Figure 1. Age-Gender Distribution of Abductees

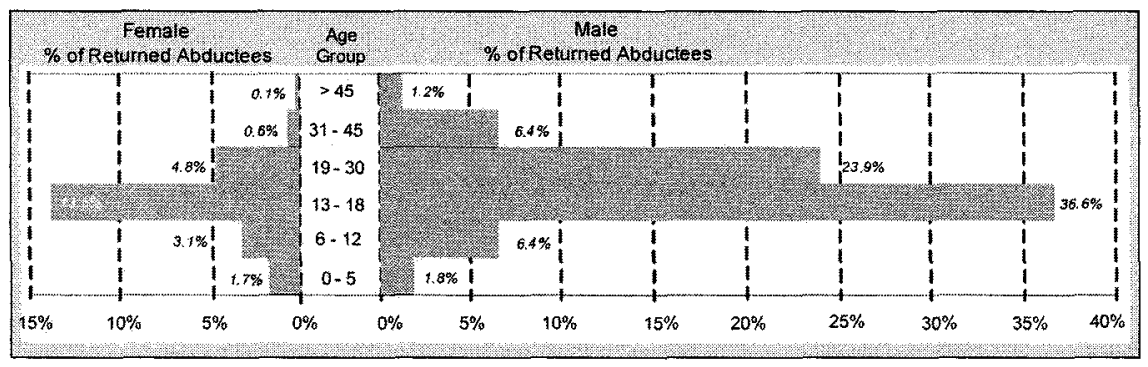

Figure by the authors. Data source: Database Project, Berkeley-Tulane Initiative on Vulnerable Populations.

The average length of abduction of returnees reporting to the eight reception centers was 342 days. The median number of days of abduction was ninety-two days. Overall, 16 percent were abducted for a week or less, 35 percent for a month or less, and 52 percent for three months or less. Twenty percent were abducted for over a year.

Length of abduction varied significantly between gender $(p<0.01)$. Girls and women, on average, were abducted for nearly two years (643 days) - more than twice the average length of abduction for boys and men (258 days). Thirty-four percent of the females had been abducted for over a year, compared to 18 percent for the males. Considering the effect of gender, the group with the longest average abduction was that of women nineteen

Figure 2. Age-Gender Distribution of Length of Abduction (in Days)

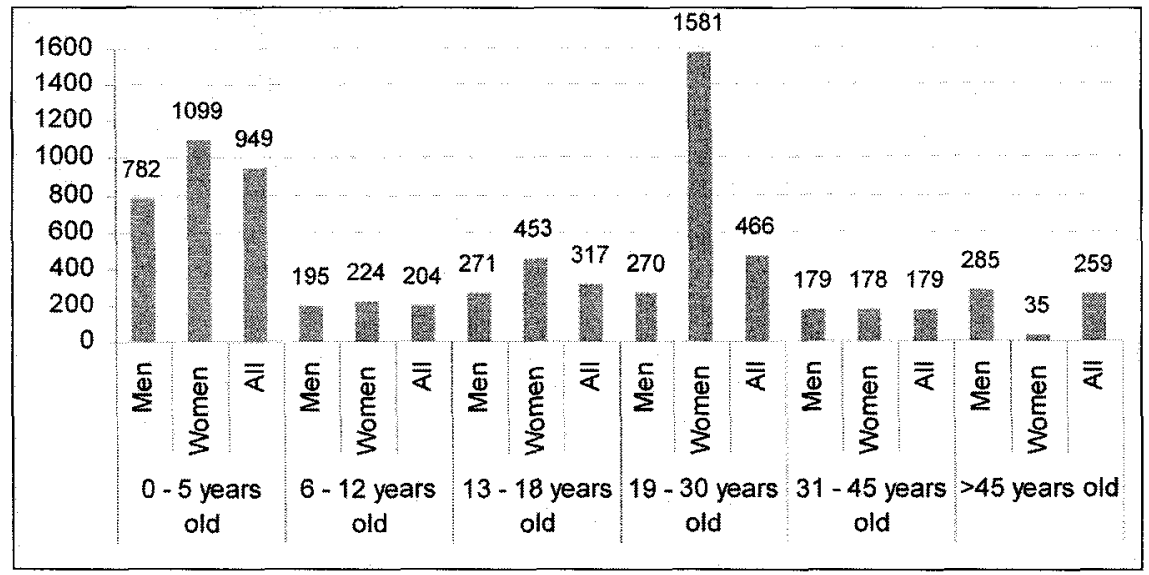

Figure by the authors. Data source: Database Project, Berkeley-Tulane Initiative on Vulnerable Populations. 
Table 1

Factors Associated with Length of Abduction

\begin{tabular}{lrrrrr}
\hline \hline Source & $\begin{array}{c}\text { Type III Sum } \\
\text { of Squares }\end{array}$ & d.f. & Mean Square & F-Statistic & $p$-value \\
& & & & & \\
Intercept & 21465810.193 & 1 & 21465810.193 & 53.045 & $<0.01$ \\
Age Group & 49276192.736 & 5 & 9855238.547 & 24.354 & $<0.01$ \\
Sex & 25479105.786 & 2 & 12739552.893 & 31.481 & $<0.01$ \\
Age Group & & & & & \\
$\quad$ * Sex & 744070790.248 & 8 & 93008848.781 & 229.837 & $<0.01$ \\
Error & 7540263268.951 & 18633 & 404672.531 & & \\
Total & 11168424557.000 & 18649 & & & \\
& & & & &
\end{tabular}

Computed using alpha $=.05 ; R$ Square $=0.161$ (Adjusted $R$ Squared $=.160)$

Table 2

Abduction Figures from Multiple Sources

\begin{tabular}{|c|c|c|c|c|c|}
\hline Source & $\begin{array}{l}\text { Time } \\
\text { period }\end{array}$ & $\begin{array}{l}\text { Number } \\
\text { of Adults }\end{array}$ & $\begin{array}{l}\text { Number } \\
\text { of Children }\end{array}$ & $\begin{array}{c}\text { Age } \\
\text { Unknown }\end{array}$ & Total \\
\hline \multicolumn{6}{|c|}{ Reception Center Database Project including Rachele reception center data. } \\
\hline & $\begin{array}{c}1986-2001 \\
2002-2006 \\
\text { Year unknown } \\
\text { Total }\end{array}$ & $\begin{array}{c}3,474 \\
4,612 \\
388 \\
8,474\end{array}$ & $\begin{array}{c}4,446 \\
10,232 \\
1,726 \\
16,404\end{array}$ & $\begin{array}{c}59 \\
100 \\
194 \\
353\end{array}$ & $\begin{array}{c}7,979 \\
14,944 \\
2,308 \\
25,231\end{array}$ \\
\hline \multicolumn{6}{|c|}{ Community canvassing Database (CPA) } \\
\hline & $\begin{array}{c}1986-2001 \\
2002-2003 \\
\text { Total }\end{array}$ & $\begin{array}{c}14,984 \\
2,318 \\
17,302\end{array}$ & $\begin{array}{c}15,723 \\
2,394 \\
18,117\end{array}$ & $\begin{array}{c}132 \\
93 \\
225\end{array}$ & $\begin{array}{c}30,839 \\
4,805 \\
35,644\end{array}$ \\
\hline \multicolumn{6}{|c|}{ UNICEF } \\
\hline & 1989-2001 & 18,399 & 9,818 & 386 & 28,603 \\
\hline
\end{tabular}

to thirty years old, with an average of roughly four and one half years $(1,581$ days) spent in captivity. This group represents about 5 percent of all former abductees. Among men, length of abduction showed less variation across age groups (except for infants).

At the multivariate level, we found that gender and age were associated with length of captivity. The main effect of age and gender were both statistically associated with the length of captivity as well the interaction between them (F-Statistic $=229.8, p$-value $=0.0001)$. For the younger age groups 
$(0-5,6-12,13-18$, and $19-30$ years), females were in captivity longer than males. However, for the older age groups ( $31-45$ and $45+$ years), men were in captivity longer than women.

Three factors may explain why women nineteen to thirty years old stayed with the LRA for long periods of time. First, the LRA abducts girls and women to serve as long-term sexual partners and domestic servants to commanders. Fourteen percent of females who passed through a reception center in the district of Apac self-reported that they had been "given" to commanders, and 10 percent reported giving birth while in captivity. Second, women forced to serve as "wives" are likely to be kept in encampments and villages located some distance from combat zones, offering less opportunity to escape, surrender, or to be captured by army troops. Finally, women who have babies while in captivity may fear trying to escape or simply chose not to leave the rebel group.

A mapping of the place of origins of LRA returnees suggests that higher numbers of registered abducted people come from east of Gulu and south of Kitgum. Generally, they also came from urban centers and their environs. Fourteen sub-counties had at least 500 registered former abductees. They were all located in the Acholi districts of Amuru, Gulu (Atiak, Bungatira, Lamogi, Awach, Koro, Odek, Lalogi, Paicho), Kitgum (Kitgum Matidi, Labongo-Amida), and Pader (Atanga, Acholi-Bur, Pajule). However, the mapping shows that other districts have also been affected, including non-Acholi areas.

Figure 3. Mapping of Abduction

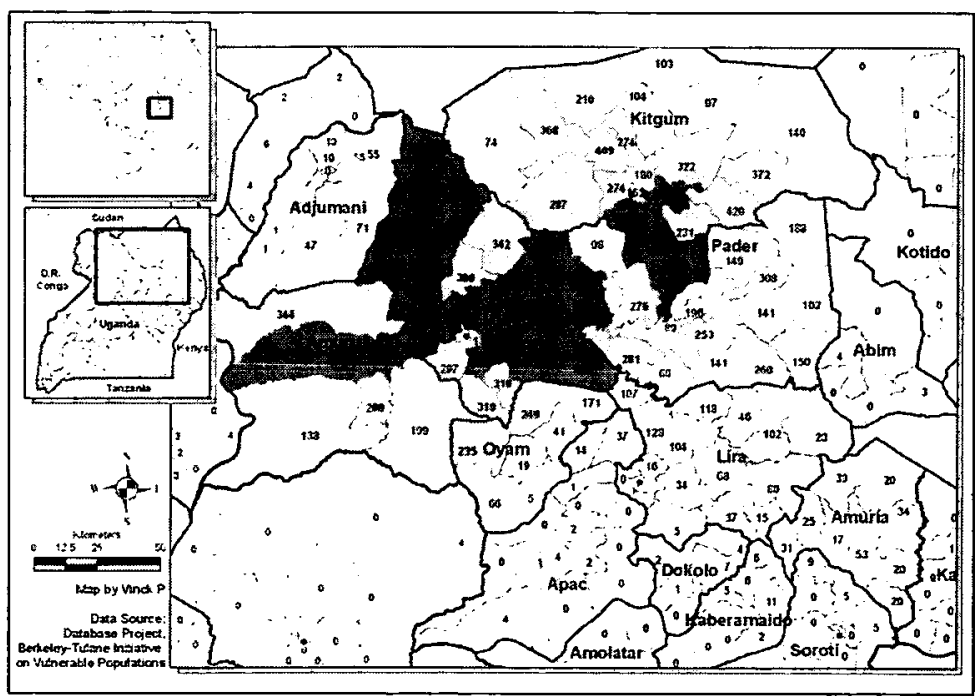

Figure by the authors. Data source: Database Project, Berkeley-Tulane Initiative on Vulnerable Populations. 
The 25,231 registered LRA returnees is not an exhaustive count of all abducted people in northern Uganda. Many of those abducted by the LRA have not returned, while others have escaped and not passed through a reception center. Still others may have passed through a reception center but were not registered or their documentation was lost or destroyed. Furthermore, recent studies estimate that less than half of all child returnees pass through a reception center. ${ }^{7}$

Despite these gaps in information, we were able to triangulate the reception center data with data collected by UNICEF and the Concerned Parents Association (CPA) to estimate the total number of LRA abductions. The UNICEF data suggests that 28,603 people, including 9,818 children, were abducted by the LRA between 1986 and 2001. Data from the CPA, a local group of parents whose children were abducted, suggests that 30,839 people, including 14,984 children, were abducted during the same time period. Neither of these organizations have data on abductions between 2002 and 2006. However, the reception center data indicates that more than 3,474 adults and 10,232 children were registered over that period of time. If the 1986-2001 rates of registration of 25 percent for adults and 50 percent for children are applied, ${ }^{8}$ the total number of abductions over the period between 2002 and 2006 can be estimated, at roughly 19,000 adults and 22,000 children. Considering a 50 percent efficacy increase by the reception centers on registering abducted people after 2001, the rate of registration would be approximately 35 percent for adults and 75 percent for children, with a total number of abductions estimated at 14,000 adults and 16,000 children. Therefore, it is estimated that the LRA abducted approximately 54,000 to 75,000 people, including 25,000 to 38,000 children, between 1986 and 2006. These are conservative estimates. A recent cross-sectional survey of 2,875 adults randomly selected in eight districts of northern Uganda found that 36.8 percent of the respondents reported experiencing abduction (48.8 percent in the Acholi districts); 20.8 percent for over a week and 2.3 percent for over a year. Among those abducted, just 13.4 percent reported going through a reception center. ${ }^{9}$

7. Id.; Tim Allen \& Mareixe Schomerus, A Haro Homecoming: Lessons Learned from the Reception Center Process in Northern Uganda, An Independent Study, USAID \& UNICEF 2006), available at http://pdf.usaid.gov/pdf_docs/PNADI241.pdf.

8. UNICEF, Abductions in Northern and SOUtHWESTERn UGanda: 1986-2001 (2001).

9. WHEN THE WAR EnDS, supra note 5. 


\section{INTERPRETATION}

These findings have important implications for the government of Uganda, the International Criminal Court (ICC), and international humanitarian organizations. First, the high number of abductions suggests that the Ugandan government has largely failed to protect civilians from abductions and other assaults by the LRA in northern Uganda. It is imperative that the Ugandan government take greater measures to ensure the safety of civilians, particularly children and youth who are at a higher risk of being abducted by the LRA.

Second, while the whereabouts of most of the LRA abductees is still unknown, it is known that some abductees, possibly including 1,000 to 3,000 children, remain with the LRA, and thousands of others have died on the battlefield or at the hands of their abductors. Studies in several war-torn countries have shown that families wish to know the fate of their missing relatives and, if they have died, to receive their remains. ${ }^{10}$ Given the tens of thousands of people still missing after being abducted by the LRA, the Ugandan government should establish a commission to investigate their whereabouts and the circumstances surrounding their disappearance.

Third, a two-pronged approach needs to be implemented to help LRA returnees reintegrate into their communities. International humanitarian organizations should establish medical and psychosocial programs to care for LRA returnees who suffer from physical and psychological problems. At the same time, community-based programs need to be created to provide all children and youth in northern Uganda, including LRA returnees, with educational opportunities, vocational skills, meaningful jobs, and leadership training.

Finally, a standardized system for collecting and analyzing data on former child soldiers needs to be created to assist the work of reception centers and Disarmament, Demobilization, and Reintegration (DDR) programs worldwide. Such a system will enable these institutions to record basic demographic and medical information about child soldiers, as well as qualitative information about their experiences in captivity. Having information in a standardized form will also improve the ability of data managers to quickly retrieve and cross-reference information as they try to reunite former child soldiers with their parents and other relatives. Furthermore, the analysis of aggregate data on child soldiers can reveal patterns of abduction and captivity that could be useful to ICC prosecutors and others investigating war crimes, including cases of forced conscription. Finally, a standardized database will help centers and DDR programs track former child soldiers who have returned to their families and provide follow up services.

10. Eric Stover \& Rachel Shigekane, Exhumation of Mass Graves: Balancing Legal and Humanitarian Needs, in Mr Neichbor, Mr Enemy: Justice and Communitr in the Aftermath of MAss Atrocirr 85 (Eric Stover \& Harvey M. Weinstein eds., 2004). 